\title{
Recycling of waste latex paint in concrete: a review
}

\begin{abstract}
With over 16 million gallons of latex paint being discarded every year it is the largest, by volume, liquid hazardous waste in the United States. Waste latex paint is difficult to recycle and hazardous to the environment due to the volatile organic compounds it contains. Several methods exist for disposing WLP including paint swaps, combustion, and by drying and discarding in a landfill. Many communities are moving to dispose waste latex paint by drying and placing in a landfill due to budgetary constraints. Nonetheless, this is the least environmentally friendly technique since it creates a need for new resources. Concrete is the most widely used construction material in the world. However, normal concrete has several deficiencies including low tensile strength, low weight to strength ratio, and low chemical resistance. Polymer-modified concrete was created to overcome several disadvantages of normal concrete. Despite its superior properties, latex-modified concrete use is limited to special applications due to the associated cost premium. These special applications include bridge overlays, anti-corrosive linings, and water-proofing, parking decks, and patching deteriorating concrete. The current literature shows promise of recycling waste latex paint in concrete to produce an economic latex-modified concrete. Studies have shown that recycling latex paint in concrete can produce a superior concrete while safely disposing of a harmful hazardous waste.
\end{abstract}

Keywords: waste latex paint, sustainability, latex-modified concrete, recycling, green construction, polymer-modified concrete, liquid, human consumption, natural rubber, styrene butadiene rubber, lower chloride

\author{
Volume 2 Issue 2 - 2018
}

\author{
Aly Said,' Oscar Quiroz \\ 'Associate Professor,The Pennsylvania State University, \\ University Park, PA 16802, USA \\ 2Project Engineer at Slater Hanifan Group, Las Vegas, Nevada, \\ USA \\ Correspondence: Aly Said, Department of Architectural \\ Engineering, The Pennsylvania State University, University Park, \\ PA I6802, USA, Tel $8 \mid 4863$ 2087, Fax 814863 4789, \\ Email aly.said@engr.psu.edu
}

Received: January 0I, 2018 | Published:September 21, 2018
Abbreviations: WLP, waste Latex Paint; LMC, latex-modified concrete; PMC, polymer modified concrete; SBR, styrene butadiene rubber; PLP, processed latex pigment

\section{Introduction}

Concrete is the construction industry's most used material. Only water surpasses concrete in human consumption. Portland cement is a necessary material in concrete that binds the aggregates. However, it requires a high amount of energy to be produced. Reports attribute up to $5 \%$ of the world's annual $\mathrm{CO}_{2}$ emissions to cement production. Portland cement concrete has several drawbacks including weak tensile capacity, vulnerability to chemical attack, and low strength to weight ratio. There have been several admixtures and techniques that allow concrete to overcome its vulnerabilities, including using polymers. ${ }^{1,2}$

\section{Polymer modified concrete}

Polymer modified concrete (PMC) is a special concrete developed to address some of the deficiencies found in standard portland cement concrete. Natural rubber was the first polymers used to produce PMC in the 1930s, but due to cost limitations and the high-demand for natural rubber in wartime, the use of PMC was very limited. Synthetic polymers became widely accepted in the 1960's. Styrene butadiene rubber (SBR) became commonly used in bridge deck overlays after a study by the Dow Chemical Company and the Michigan Highway Department. The study found that SBR concrete had significantly lower chloride permeability than ordinary concrete. ${ }^{2,3}$ Latex-modified concrete (LMC) is a sub-category of PMC, where latex is the polymer in use. It was created to overcome the well-known shortcomings of normal concrete. However, latex additives, priced between $\$ 4-\$ 5$ per gallon, can increase the cost of a cubic yard of concrete from $\$ 56$ to $\$ 156$. Therefore, LMC is not used for general applications. ${ }^{2}$
According to several online wholesale liquidators, the price of latex paint can range from $\$ 2.50$ to $\$ 4.50$ per gallon depending on color and quantity. ${ }^{4}$ However, if waste paint bound for disposal by a manufacturer or a municipality, it will come with credit towards disposal. For commercial production of LMC, styrene butadiene rubber (SBR) is a synthetic rubber latex that is the most commonly used to produce. LMC, like polymer-modified concrete, has superior qualities over normal portland cement concrete. The quality of the LMC is determined by polymer type, polymer-cement ratio, watercement ratio, air content, and curing conditions. ${ }^{1}$ According to Ohama $^{1}$ the presence of polymers during hydration improves the bond between hydrated cement and aggregates. Once hydrated, a bond is created between calcium from cement and polymer. The polymer and aggregates form a coordination complex around the calcium. The effect of the chemical bond on the LMC is governed by the polymer volume.

\section{Recycling of waste latex paint practices}

The United States sells an estimated 650 million gallons of paint every year, out of which, 35 million gallons of latex paint remain unused. Waste Paint can come from two sources, residential leftovers and commercial rejects from customer returns. Paint is a concern for the United States due to its high volume, cost to manage, its levels of volatile organic compound, fungicides, and hazardous metals from older paints. However, paint has high potential for reuse, recovery, and recycling. ${ }^{5}$ Paint is composed of binders, pigments, solvents, extenders and additives, and antimicrobials. A binder is a non-volatile film used to bind the pigments together. Acrylate is commonly used as a binder in latex paint. Binders typically make up $25 \%$ of the volume in latex paint. Pigments, which make up $15 \%$ of the volume, are fine particles that provide color to paint. Solvents are used to dissolve or break up the latex paint constituents. They are made from 
organic liquids or water and make up 50\% of the latex paint volume. Extenders and additives alter or enhance several properties in paint including thickness, drying, skinning, and corrosion resistance. On average, extenders and additives make up $10 \%$ of the volume in latex paint. Finally, antimicrobials are used in regions with high humidity to stop paint from spoiling or to prevent algae and fungi once the paint has been applied. ${ }^{6}$

The large amount of WLP creates a need to dispose the paint and use its valuable resources. ${ }^{5}$ The most common method to dispose WLP is through solidification, which is then disposed of in a landfill. This method is the least preferred because it consumes raw resources. WLP discarded in a landfill has the potential to contaminate the groundwater. However, with decreasing budgets, communities are adopting paint solidification. ${ }^{7}$ Some communities attempt to use the WLP for their own needs. For example, in Hernando County, Florida there is a requirement that a cover must be placed over any landfill to protect from odor, disease, and wind gusts. Therefore, the landfill sprays a WLP and water mixture onto its surface as the daily cover. ${ }^{6}$ Furthermore, WLP is used as fuel in incineration chambers, which is not an effective use of the valuable materials found in latex paint. Other communities have allowed for a neighborhood paint collection, which is then stored in the neighborhood and the paint becomes available to community members. Approximately, half of all paint collected in its original container is suitable for reuse. Such process involves neighborhood members collecting the paint and storing it until needed. Recycled paint can be of high quality and comparable to new paint if filtered and with additives. Segala ${ }^{7}$ studied a technique to recycle paint known as processed latex pigment (PLP). Sources for PLP paint include automobile manufacturing plants, entertainment production, maintenance companies, and professional painters. PLP is a patented method for recycling industrial paint sludge, watertreatment sediment, and leftover latex paint. PLP is shipped to portland cement plants to use the PLP as an additive for special cements or use the PLP as a raw material for the kiln feedstock. PLP can replace silica, aluminum, iron, and calcium carbonate.

\section{Recycling waste latex paint in concrete}

The existing literature suggests that recycling WLP as a latex additive in concrete is beneficial. Several studies have investigated the ability of WLP to reproduce the properties of SBR. One of the pioneering studies was performed by Nehdi and Sumner ${ }^{8}$ funded by the local municipality trying to address the issue of residential waste latex paint disposal in an economic and environmentally friendly manner. It was suggested that recycling WLP in sidewalk is a good choice given that durability is more valuable than strength in such application. Two sets of concrete mixes where WLP was used to replace virgin latex in the first, while WLP was used to replace mixing water in the second. It was found that increasing the WLP replacement of virgin latex caused a decrease in compressive strength and flexural strength. The mixes where WLP replaced water exhibited enhanced workability and finishing, more appealing color, and better durability to surface scaling and aggregate pop out. Furthermore, a field demonstration sidewalk was built to ensure its actual performance. ${ }^{9}$ Another study was performed by Mohammed et al., ${ }^{10}$ where a varying percentage of WLP was replaced in mixtures and compared to a normal concrete mix and a mix containing $15 \%$ virgin latex. The study found that WLP enhanced the workability and the flexural strength of concrete, however, a decreasing tendency in compressive strength was observed. Various curing conditions (air, moist, and water) produced adequate compressive strength results for concrete incorporating WLP. It was concluded that WLP addition produced a cementitious matrix with a relatively denser microstructure and enhanced long-term durability. The durability of concrete under various testing regiments was enhanced due to WLP addition. Moreover, the results of leaching tests on aged concrete specimens incorporating WLP indicated negligible emission of toxic metals. The study recommended the use of a $15 \%$ WLP partial replacement for mixing water in concrete for nonstructural concrete elements such as sidewalks, highway median barriers, and concrete blocks. Almesfer et al., ${ }^{11}$ investigated the use of WLP in low strength concrete for masonry blockfill. The study examined various ratios of WLP addition in concrete $(0-20 \%$ paint replacement of water) to assess the optimum dosage. The study looked into the impact of WLP on compressive strength, workability, tensile strength, elastic modulus of elasticity. The study showed that WLP can interact negatively with some commercial admixtures. Nonetheless, the overall impact of WLP on fresh and hardened properties is positive. A follow up study by Almesfer and Ingham ${ }^{12}$ focused on a low strength standard $20 \mathrm{MPa}$ concrete mix. Paint from various sources was examined. The use of WLP in concrete was found to enhance workability, but compressive strength was reduced yet remained adequate for intended use. WLP slightly enhanced the durability characteristics of concrete. The concrete phase analysis indicated that the addition of WLP produced concrete that was not as dense as normal concrete in terms of microstructure. The study recommended a dose of $12 \mathrm{~L} /$ $\mathrm{m}^{3}$ of WLP for use in non-structural $20 \mathrm{MPa}$ applications such as sidewalks and driveways. Assaad ${ }^{13}$ investigated the interaction of WLP with water reducers and its effect on concrete rheology. Paint from various sources were used to produce concrete. The study showed a dependency of concrete rheology on WLP constituents and some potential for incompatibility when polycarboxylate-based water reducers are used. A follow up study on the bond slip performance of WLP concrete showed an improved performance with the addition of WLP. ${ }^{14}$ Said et al. ${ }^{15}$ investigated the use of WLP in bridge overlays. Two WLP mixes and two commercial SBR mixes were compared to normal concrete. The study found that WLP concrete can have similar performance to SBR concrete while outperforming normal concrete in terms of strength development and abrasion resistance. ${ }^{16} \mathrm{WLP}$ helped concrete develop a refined pore structure while lowering porosity. ${ }^{17}$ The performance was dependent on the quality of the recycled paint. The study concluded similar results for pervious concrete containing WLP. ${ }^{18}$

\section{Discussion}

Based on the authors experience with this research area and the current literature, WLP is a very viable way of recycling waste latex paint while producing higher quality concrete, in terms of durability, and averting the disposal of this hazardous material into landfills. Furthermore, it seems clear that the constituents of WLP used significantly impact the quality of the produced concrete. Such issue is very difficult to manage given the number of manufacturers, their various lines of products and additives that may be introduced by users. Additionally, manufactures do not reveal the exact proportions of their paint products, which may even change due to evaporation/ paint dying out in the course of its use. This creates a hurdle in implementation since trial batches may be needed to evaluate the produced concrete given that paint from various sources will be mixed. In the course of the author's research, it was revealed that manufacturers struggle with the cost of recycling paint returns from 
hardware stores similar to municipalities. There may be an opportunity in the paint industry working with states to set a manufacturing standard that ensure compatibility of waste latex paint with recycling into concrete production. The existing body of literature and the field demonstrations confirm that the use of WLP in concrete production for low strength concrete applications is very viable. The produced concrete is generally better in terms of durability. Most studies recommended the use of concrete in non-structural applications, especially in those where durability is more important than strength. However, the reported strength reduction in some studies can be addressed through mix design. Special attention should be given to the interaction of paint and commercially available concrete admixtures to ensure compatibility

\section{Conclusion}

From the reviewed literature, the use of WLP to produce an economic LMC for specialized applications such as overlays of mass applications such as pavements and sidewalks is very feasible.

\section{Acknowledgements}

Provide list of individuals who contributed in the work and grant details.

\section{Conflict of interest}

The author has no known conflicts of interest with any involved entity or person(s).

\section{References}

1. Ohama Y. Handbook of polymer-modified concrete and mortars: Properties and process technology. Building materials science series. Park Ridge, N.J: Noyes Publications. 1995;13:14-45.

2. Ramakrishnan V. United States, National Research Council, and American Association of State Highway and Transportation Officials, LatexModified Concretes and Mortars. National cooperative highway research program synthesis of highway practice. Washington, DC: Transportation Research Board, National Research Council. 1992;179.

3. Clear KC, Chollar BH. Styrene-butadiene latex modifiers for bridge deck overlay concrete. Washington D.C.: Department of Transportation. FHWA-RD-78-35. 1978;1:117.
4. AAA Closeout Liquidators. Building supply factory liquidation deals. $2017 ;(27)$.

5. Product Stewardship Institute. Product Stewardship Action Plan for Leftover Paint, Product Stewardship Institute, University of Massachusetts/ Lowell. 2004. 26 pp.

6. Greiner T, Velva V, Phipps A. A Background Report for the National Dialogue on Paint Product Stewardship. Product Stewardship Institute. 2004;83 pp.

7. Segala L M. Recycling of nonhazardous industrial paint sludge, nonreusable leftover latex paint, and similar materials. Metal Finishing. 2003;101(3):38-40.

8. Nehdi M, Sumner J. Recycling waste latex paint in concrete. Cement and Concrete Research. 2003;33(6):857-63.

9. Nehdi M. Recycled waste latex paint as an admixture in concrete sidewalks. Special Publication. 2004;219:131-144.

10. Mohammed A, Nehdi M, Adawi A. Recycling waste latex paint in concrete with added value. ACI Materials Journal. 2008;105(4):367-74.

11. Almesfer N, Haigh C, Ingham J. Waste paint as an admixture in concrete. Cement and Concrete Composites. 2012;34(5):627-633.

12. Almesfer N, Ingham J. Effect of waste latex paint on concrete. Cement and Concrete Composites. 2014;46:19-25.

13. Assaad JJ. Effect of Waste Latex Paints on Rheological Properties of Cement Pastes: Compatibility with Water Reducers. Journal of Materials in Civil Engineering. 2015;27(12):04015056.

14. Assaad JJ, Issa CA Effect of Recycled Acrylic-Based Polymers on Bond Stress-Slip Behavior in Reinforced Concrete Structures. Journal of Materials in Civil Engineering. 2016;29(1):04016173.

15. Said AM, Quiroz OI. Hatchett DW, et al. Latex-modified concrete overlays using waste paint. Construction and Building Materials. 2016;123:191-197.

16. Said AM, Quiroz OI. Latex-Modified Concrete Overlays Using Recycled Waste Paint. International Congress on Polymers in Concrete. 2018;465-469.

17. Quiroz OI, Said AM. Economical Bridge Overlays Using Waste Latex Paint. Special Publication. 2011;278:1-16.

18. Said AM, Quiroz OI. Innovative Polymer-Modified Pervious Concrete International Congress on Polymers in Concrete. Proceedings of the 16th ICPIC Congress in Washington D.C. 2018;243-247. 